DOI: $10.15503 /$ jecs20161.5.8

\title{
PREFACE \\ LEVELS OF RESENTMENT \\ IN THE UNIVERSITY OF THE THIRD AGE
}

\author{
ALEKSANDER KOBYLAREK, \\ Institute of Pedagogy, University of Wrocław \\ J. Wł. Dawida 1, 50-527 Wrocław, Poland \\ e-mail address: aleksander.kobylarek@gmail.com

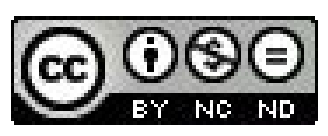

\section{ABSTRACT}

Resentment has a particular place in the University of the Third Age. Here, the activities of the organization come up against the developing personalities of the elderly and crises of personality, which intensify the phenomenon. Temporary resentment can in unfavourable circumstances temporary resentment can escalate into permanent resentment, which is more difficult to alleviate. The task of the manager is to uncover this phenomenon at a relatively early stage, and to take appropriate preventative measures in the form of long-lasting negotiation of tasks and suitable system of sharing rewards.

Key words: resentment, U3A, negative ageing, management of emotions, NGO, psychological contract

The University of the Third Age is a distinctive organization, the management of which poses an enormous challenge for the director. Here, apart from the usual problems which arise in any organization, additional problems need to be dealt with related to the specifics of ageing. Among the issues connected to ageing which make the task of management difficult, the greatest challenge is posed by emotional dysregulation, related to specific emotional reactions. Among these are typical mood swings - 'the yo-yo effect'- and the experiencing of resentment. Very often the one is connected with the other, and both are characteristic of adverse ageing and are related to the psychological costs which people must bear as they get older.

The second important aspect of the management of the University of the Third Age is the fact that generally we are dealing with non-governmental organizations. These operate on a non-profit basis, supported by vouluntary work by the elderly, who are also characteristic. Here we are very often dealing with involvement in voluntary work based on emotional benefits. Obviously, the involvement of many elderly people arises primarily from acquired virtues, among which social work is ranked fairly highly, although this is not always the case. Thanks to such activities, a large percentage of the volunteers rediscover their place in society through a network of social and emotional relationships. Many of them are quite simply looking for 
appreciation. However, insofar as younger people do something out of a sense of help and suppot, for elderly people emotional benefits are just as important as altruisic motives among the young. This emotional dimension often becomes much more important, especially when emotional needs are unsatisfied for reason of loneliness, loss, or trauma following the death of a loved one. The literature of psychology and pedagogy shows that while on the one hand such an increase in emotional needs can be caused by specific - so-called critical - life events, on the other hand age itself (meaning the ageing process) is also a factor in increasing the need for affiliation and acceptance, with which the need to be appreciated is closely connected.

Thus, the director of the University of the Third Age finds himself in a fairly specific situation - managing an organization of which the formation, strength and effectiveness is dedided by the involvement of elderly volunteers with special emotional needs and at a specific stage in their life.

A crisis can very easily arise among elderly volunteers, especially those actively engaged on behalf of society, and then we are dealing with emotional exhaustion, the symptons of which are similar to professional burnout. My observation of these characteristics indicate a fairly meagre description of the phenomenon of resentment in scientific literature. Psychology shows that a characteristic trait of small children, unable to achieve a goal, is to justify themselves by explaining that it was't worth the effort anyway - a kind of recompense for their disappointment. This mechanism can be better explained in adult life by the philosophy of exaggerating our defeats and blaming others for our own failure. This typically leads to rebellion against authority, spitefulness, obstinacy and a desire for revenge, which in turn leads to destructive behaviour. In the best case scenario, it leads to retreat, inactivity and suffering in silence. In the worst scenario we may have to deal with acts of aggression and destruction. There follows an attempt to rationalize failure in the shape of unrealised needs by presenting oneself in the role of victim, who needs sympathy and who is constantly under-appreciated by others. As a consequence, those harbouring resentement either seek revenge or present themselves as the eternal victim whose requirements can never be satisfied.

Resentement is a state of mind which should be recognised as an aberration requiring therapy. It is a phenomenon in which emotions disrupt the ability for logical reasoning and make objective assessment of a given situation impossible. Those burning with resentment will seek revenge at any cost. If they don't have a sufficient influence on reality, they sabotage the actions of others, look for support from others in a similar situation and who harbour resentement to the same degree as themselves. If they are managers or team leaders, the situation becomes more complicated, because their desire for revenge and search for an atonement which cannot be attained is destructive for the group or organization.

During ten years of being the director of the University of the Third Age, I have had the opportunity to observe various types of behaviour connected with the resentment experienced by the elderly on various levels, and manifesting itself in many different ways.

The first stage is temporary resentment, which appears as a result of emotional disturbances shortly after experiencing failure, and is closely connected with the 
event which triggered the resentment. This resentment can be appeased relatively easily by offering some kind of reward which is usually expected to take a specific form, as a kind of ,payment' for a particular service. This level of resentment does not usually create any significant problem in inter-personal relationships, nor should it be an obstacle in managing a group of elderly people, such as is found in the University of the Third Age. Sometimes, however, it might be the symptom of a deeper problem and the presence of permanent resentment.

Temporary resentment can easily turn into permanent resentment, if the signs indicating its existence are ignored, and the need for recognition is denied. It appears, however, that there must be additional factors which come into play in reaching and prolonging this level of resentment. On the basis of personal observation, I can tentatively assume that there is some kind of pattern, which to a certain extentcan be verified. Presenting oneself in the role of victim evokes shame, embarrassment and consternation amongst our peers, which is sufficient gratification for showing our regret, humiliation, and sense of injustice. Such people are masters in setting emotional traps, not only for their colleagues, but primarily for their superiors. Attempts at easing the situation, comforting or emotional support usually end in the end of the conversation. Thus, people who seethe with resentment give others the sense that they are so offended and humiliated that nothing can right the hurt and injustice with which they have been treated. The more frequently and intensively the effects of helplessness and hopelessness are reflected in colleagues and superiors, the more frequently this regret and humiliation is shown. Thus, people who harbour resentment become the scourge of those around them, exhibitionistically parading their wounds and evoking emotions of regret and guilt among others. The more psychologically sophisticated of them also evoke a sense of manipulation and helplessness, because every compromise appears to be inappropriate, and nothing remains but to fall into a psychological trap. This hopeless situation is easily illustrated by transactional analysis. It is impossible to enter into a discussion or sympathise with such people, and we are unable to sufficiently recompense them for their imagined suffering. We are thus left with performing the role of the victim of other victims.

Permanent resentment cannot be alleviated, much like a festering wound into which psychological salt is constantly rubbed. Those who harbour resentment make it the centre of their daily life. One might also suspect that resentment can be a well-defined and safe (for the ego) explanation of their own situation. Those subject to this mechanism do not need to seek the reason for their failure within themselves, because they have a ready list of reasons for their misfortune. This is far better than taking responsibility for their situation in life, and confronting the truth that they themselves, and nobody else, are responsible for their mistakes.

In the case of the elderly, undoubtedly the retirement crisis, the stress of old age, and unfavourable conditions also play a part in prolonging resentment. The typical symptons of an unsuccessful ageing process are also characteristic of resentment a conviction of entitlement, aggression, a sense of hurt, constant complaining, and passivity. The ego of the elderly can be more sensitive, and thus more susceptible to resentment. 
We are also faced with a specific situation in the case of elderly volunteers working in non-governmental organisations, which is conducive to promoting and maintaining resentment. Young people working as volunteers do no expect any special gratification - they just want to do good for others out of a sense of duty. From the very beginning, the unwritten rules of the psychological contract are unambiguous and unquestionable. They work for others for their own satisfaction, without expectations of medals or glory. This is not so obvious among the elderly, who are often experiencing the crisis of ageing. Very often we have to deal with imprecise expectations of some kind of reward for fulfilling their duties. To a great extent this situation is imprecise, and the resulting expectations of the workers themselves are unclear. This places the manager in a very unpleasant and generally unexpected situation.

The most important question for the manager is how to cope with the resentment of elderly volunteers who may be experiencing the crisis of ageing or other traumatic moments in their lives. It is impossible to ignore the problem, because it will only accumulate and increase, and temporary resentment will eventually become permanent, and so reach a level which is difficult to resolve. Then we have to expect elderly volunteers leaving the organization and a decrease in its effectiveness. On the other hand, it is not really worth supporting people who are seething with resentment. Minor slights and imagined hurts turn into mountains and oceans which are impossible to overcome. In turn, it can be difficult to satisfy completely their complaints if we don't really know what the complaints are and we don't know their precise expectations.

The best strategies I have used so far in resolving the problem of resentment depend on lengthy conversations to discover the essence of the problem, and to establish the possible form of further co-operation. As in the case of motivitating people who are exceptionally unmotivated, the best method is to take it in small steps. We start with small tasks and then gradually move to more difficult and responsible tasks, not forgetting to praise and reward in the broadest sense. For those harbouring resentment it is not really about material reward, but rather an expression of acceptance in the form of praise and a meaningful place in the social structure.

It is important to recognise the problem and be aware of the possible consequences. Initial conversations with seniors harbouring resentement should be aimed at making them aware of the character of the phenomenon, and to make a preliminary assessment of the kind of resentment we are dealing with. We should bear in mind the emotional and moral atmosphere which is particularly important in the education of adults - appropriate conditions conducive to deeper thought, time to make constructive decisions and participate in new activities, and a gradual increase in difficulty. Care and delicacy in approaching the problem is recommended, otherwise an eruption of emotions and an escalation of the problem ensues. Above all, it should be remembered that resentment is a result of the domination of negative emotions over rationality. In this situation, reason comes into play only when emotions subside, and this sometimes requires a lot of patience, understanding and empathy. If reconcilliation is unsuccessful, both sides lose, because the manager cannot give in to emotion and loses an effective worker, and the elderly volunteer probably loses the possibility of cementing their position in the group as a reasonable and responsible individual. 